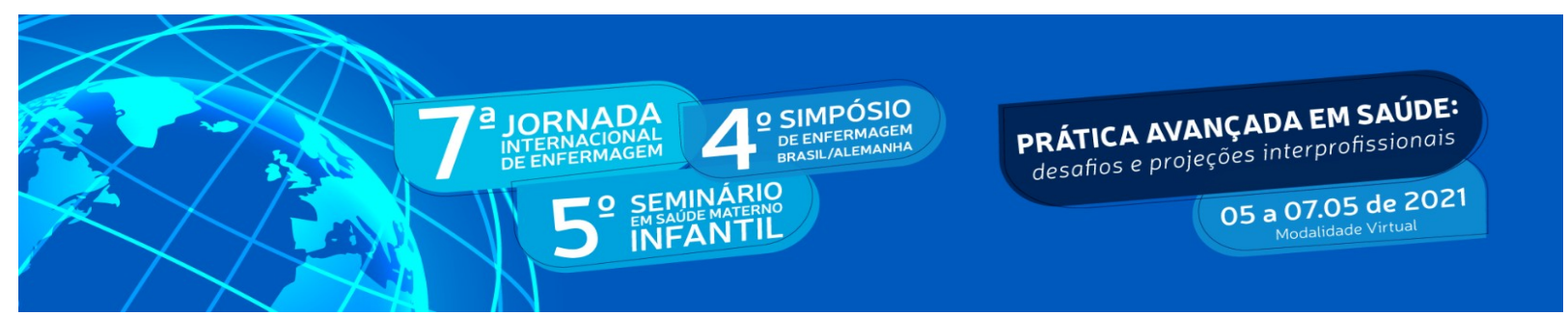

DOI: http://doi.org/10.48195/jie2021-024

\title{
DESAFIO DO SERVIÇO DE CONTROLE DE INFECÇ̃̃O HOSPITALAR NA NOTIFICAÇÃO COMPULSÓRIA DE SRAG
}

\author{
Eduardo Júnio Sobrinho da Silva'; André Luiz de Souza Braga²
}

\begin{abstract}
RESUMO
Objetivo: relatar a experiência vivenciada no processo de notificação e registro de Síndrome Respiratória Aguda Grave (SRAG), durante a pandemia do COVID-19, pelo Serviço de Controle de Infecção Hospitalar (SCIH) e suas implicações na tomada de decisão. Método: estudo descritivo de relato de experiência, realizado em um hospital privado de grande porte localizado na região norte fluminense do estado do Rio de Janeiro, com aproximadamente 200 leitos. Resultado: adequações necessárias foram feitas para que não houvesse atrasos nos serviços, acúmulo de pendências, e o negligenciamento de outras atividades competentes ao $\mathrm{SCIH}$ em detrimento deste acréscimo de trabalho, principalmente no aumento significativo de notificação compulsória por SRAG. Conclusão: a experiência ratificou-se a extrema importância o SCIH, diante da pandemia de um agravo emergente para atender todas as demandas necessárias para qualquer processo voltado ao controle e assessoramento de infecção hospitalar dentro do hospital.
\end{abstract}

Palavras-chaves: Infecções por Coronavírus; Monitoramento Epidemiológico; Notificação Compulsória; Síndrome Respiratória Aguda Grave; Vigilância Epidemiológica.

\begin{abstract}
Objective: to report the experience in the process of notification and registration of Severe Acute Respiratory Syndrome (SRAG), during a pandemic of COVID-19, by the Hospital Infection Control Service (SCIH) and their responses in decision making. Method: a descriptive study of an experience report, carried out in a large private hospital located in the northern region of the state of Rio de Janeiro, with approximately 200 beds. Result: the adjustments were made so that there would be no delays in services, the accumulation of pending issues, and the neglect of other competent activities to $\mathrm{SCIH}$ to the detriment of this increase in work, mainly in the significant increase in compulsory notification by SRAG. Conclusion: an experience confirmed the extreme importance in the SCIH, in
\end{abstract}

\footnotetext{
${ }^{1}$ Enfermeiro. Pós-graduando em Controle de Infecção em Assistência à Saúde pela Escola de Enfermagem Aurora de Afonso Costa da Universidade Federal Fluminense (EEAAC/UFF). Especialista em Enfermagem em Cuidados Intensivos com Ênfase no Cliente Adulto/Idoso (EEAAC/UFF). E-mail: sobrinhoedu@hotmail.com

${ }^{2}$ Enfermeiro e Licenciado em Enfermagem (UGF) e Odontólogo (FONF/UFF). Habilitado em Saúde Pública (UGF). Doutor em Ciências do Cuidado em Saúde (EEAAC/UFF). Mestre em Ensino de Ciência da Saúde e do Ambiente (Unipli). Especialista em Formação Pedagógica em Educação na Área de Saúde (Fiocruz). Especialista em Vigilância Sanitária (Unipli). Especialista em Controle de Infecção em Assistência à Saúde (EEAAC/UFF). Avaliador Ad Hoc de Cursos de Graduação (INEP/MEC). Membro efetivo do Núcleo de Pesquisa em Cidadania e Gerência em Enfermagem (Necigen - EEAAC/UFF). Docente da Universidade Federal Fluminense. E-mail: andre.braga@globo.com
} 


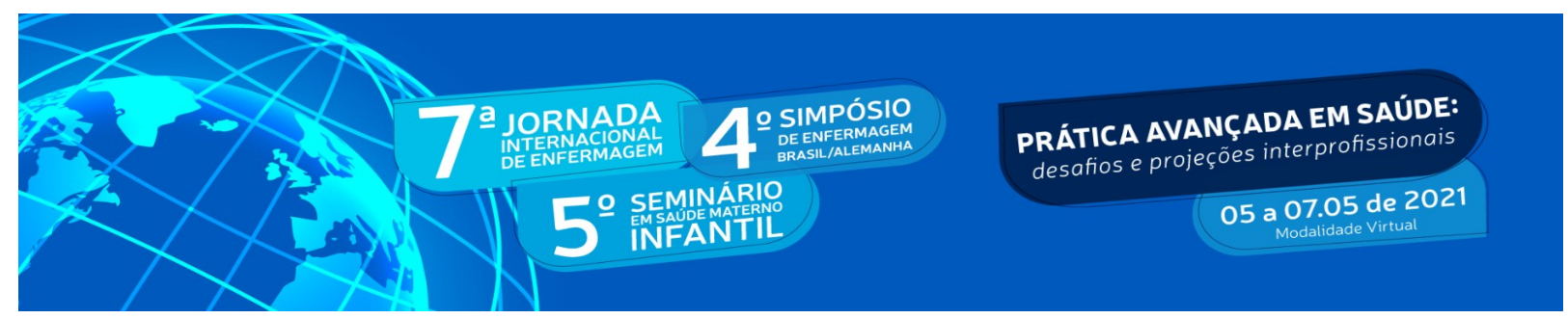

view of the pandemic of an emerging disease to meet all the necessary demands for any process aimed at the control and evaluation of hospital infection in the hospital.

Keywords: Coronavirus infections; Epidemiological Monitoring; Compulsory Notification; Severe Acute Respiratory Syndrome; Epidemiological surveillance.

\section{INTRODUÇÃ̃O}

A vigilância da Síndrome Respiratória Aguda Grave (SRAG) foi criada em 2009, em decorrência da pandemia de influenza pelo vírus H1N1. O sistema, inicialmente limitado a notificar acometidos pelos vírus influenza no país, se aperfeiçoou e incorporou o acompanhamento de outros vírus respiratórios, aumentando a abrangência de sua vigilância. O caráter sindrômico dessa vigilância permite monitorar o comportamento dos vírus respiratórios sazonais e a introdução de novos agentes etiológicos (RIBEIRO, 2010).

Em dezembro de 2019, um surto de uma nova doença provocada pelo coronavírus (COVID-19, causada pelo Coronavírus da Síndrome Respiratória Aguda Grave - SARS-CoV2) foi relatado em Wuhan, China, se apresentando como um dos maiores desafios sanitários em escala global deste século. Apresenta-se com sintomas leves, outros, sintomas graves, e ainda, tendo indivíduos portadores assintomáticos, inicialmente, como manifestações de sinais e sintomas respiratórios (SILVA; MAIA; SOUZA, 2020).

Este cenário constituído representa um grave problema de Saúde Pública, de especial interesse no campo da Epidemiologia, já que se podem produzir estatísticas, estimar incidências, mapear o curso da doença, apresentar dados demográficos, apontar comorbidades mais relacionadas, formular planos de contingência, elaborar projetos de educação e pesquisa para prevenção do contágio, entre outros fatores, que ofertem informações qualificadas para decisões mais assertivas.

A ocorrência da subnotificação dos casos de COVID-19, que são obrigatórias em até 24 horas, para as autoridades competente é frequente. A notificação é compulsória, oportuniza o monitoramento de casos, principalmente os hospitalizados, contudo observa-se que muitas variáveis influenciam para tal situação, dentre elas a não consagração da atividade como essencial, mesmo tendo a testagem do vírus SARS-CoV-2, incorporada à vigilância da SRAG e registrada no Sistema de Informação de Vigilância Epidemiológica da Gripe (SIVEP- 


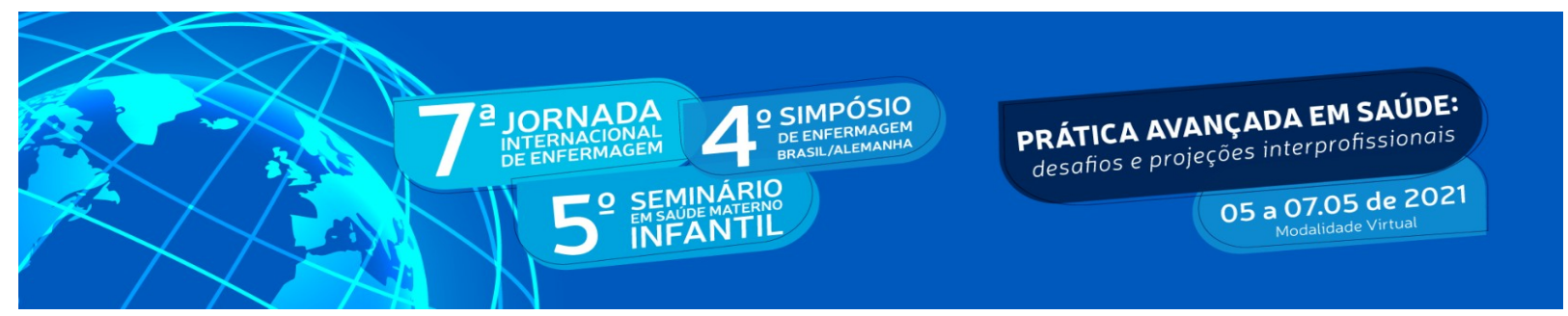

Gripe). Tal deficiência acarreta para gestores, por vezes, decisões pouco assertivas (NIQUNI et a., 2020).

\section{OBJETIVO}

Relatar a experiência vivenciada no processo de notificação e registro da Síndrome Respiratória Aguda Grave (SRAG), durante a pandemia do COVID-19, pelo Serviço de Controle de Infecção Hospitalar (SCIH) e suas implicações na tomada de decisão.

\section{METODOLOGIA}

Trata-se de um estudo descritivo de relato de experiência, em consonância com os pensamentos de Marconi e Lakatos (2017) quando descrevem a experiência pessoal, idiossincrática, como importante elemento para subsidiar a pesquisa.

Realizado em um hospital privado do norte fluminense/RJ, com 200 leitos, emergência, internação, unidades de terapia intensiva (UTIs), centro de cirurgia eletivas e pequenas cirurgias emergenciais.

\section{RESULTADO E DISCUSSÃO}

Ao iniciar este relato, torna-se imperativo situar, dentro da legislação vigente, o SCIH. Prevista na Portaria $\mathrm{n}^{\mathrm{o}}$ 2616/98 do MS, o serviço possui uma equipe mínima formada por: médico, enfermeiros e técnico de enfermagem e com a execução das principais atribuições, descritas: planejar, executar e avaliar um programa de controle de infecção hospitalar; manter a vigilância epidemiológica ativa das infecções hospitalares (MINISTÉRIO DA SAÚDE, 1998).

Contudo, na instituição relatada, não há um Núcleo de Vigilância Hospitalar (NVH), setor inerente ao SCIH, conforme trata a Portaria $\mathrm{N}^{\mathrm{o}} 2.254 / 2010$, que: institui a Vigilância Epidemiológica em Âmbito Hospitalar, define as competências para os órgãos da União, para 


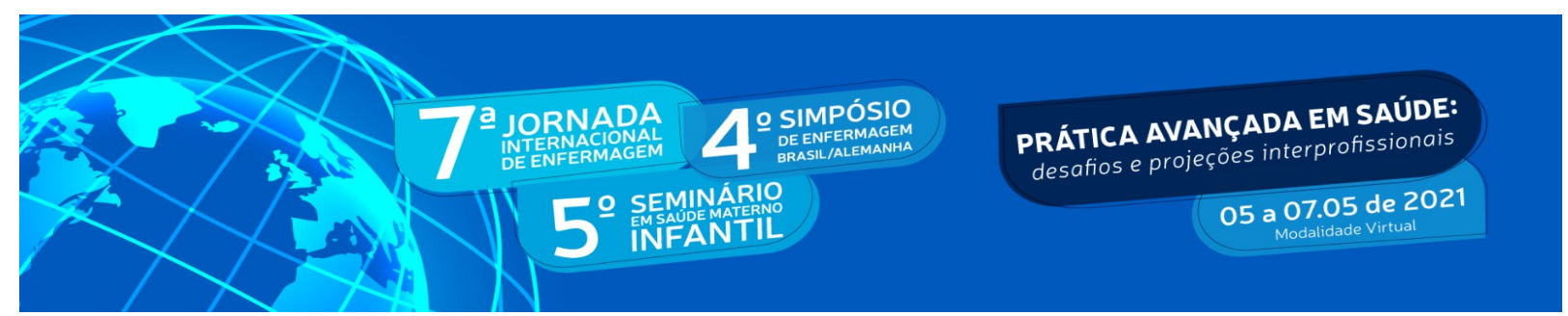

a qualificação das unidades hospitalares de referência nacional e define também o escopo das atividades a serem desenvolvidas pelos Núcleos Hospitalares de Epidemiologia (MINISTÉRIO DA SAÚDE, 2010).

Assim, o SCIH na instituição relatada, que engloba o trabalho de epidemiologia, apesar de não existir o NVH, traz um déficit no rastreamento de qualquer notificação compulsória, principalmente nos casos de SRAG-Hospitalizados (pacientes internados por COVID-19) e eventualmente no e-SUS VE - https://notifica.saude.gov.br/login (pacientes que buscam atendimento emergencial e são liberados para isolamento domiciliar). Dificultando o monitoramento e as decisões do serviço.

\section{Do atendimento de suspeita e/ou caso positivo do COVID-19 à problematização da notificação por SRAG}

De partida, com o surgimento da pandemia pelo COVID-19 foi restruturado todo processo de atendimento - segurança do paciente e do profissional. $\mathrm{Na}$ emergência, tanto para adulto quanto para criança, foi criado subdivisões: atendimento de rotina, denominado por "área limpa" e atendimento respiratório - COVID, este, composto por médicos, equipe de enfermagem, de higienização e fisioterapia. Para esta nova demanda toda a equipe multidisciplinar do hospital foi treinada pelo $\mathrm{SCIH}$, por processos internos e em consonância com MS, capacitando-os na paramentação de equipamentos de proteção individual (EPIs), uso e armazenamento da máscara N95 e nas coletas de Antígeno (antígeno rápido $\mathrm{N}$ nucleocapsídeo) e swab naso-orofaringe para RT-PCR (teste de reação em cadeia da polimerase via transcriptase reversa). Considerado método padrão ouro de referência para confirmação da infecção. (LIMA et al., 2020)

Todo paciente que chegava ao pronto atendimento com história clínica por síndrome gripal (SG), com quadro de febre e sintomas respiratórios (tosse seca, coriza e dispneia com saturação de oxigênio - SatO2 < 92\%), era gerado uma senha; passava pela classificação de risco, e após, o atendimento médico em consultório, e se necessário coletado RT-PCR (prescrito e encaminhado para laboratório terceirizado). Era entregue um número de protocolo 


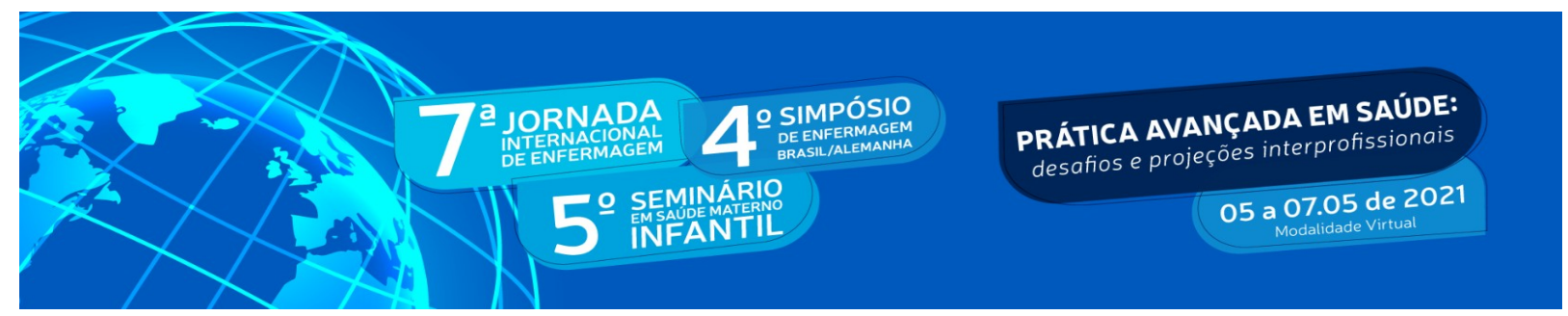

para retirada do laudo via sistema do hospital em até $72 \mathrm{~h}$, e assim liberado para isolamento domiciliar.

Ressalta-se que a SG, causada pelo vírus influenza, circula e acomete um número expressivo da população mundial a cada ano. Ela se manifesta de forma branda ou grave, podendo levar os indivíduos a morte, especialmente aqueles que compõem grupos de risco, evidenciando assim, a sua importância no monitoramento do COVID-19 (CUGINI et al., 2010).

O paciente que apresentava quadros mais graves, tais como, insuficiência respiratória aguda, edema agudo de pulmão, etc, era remanejado para sala vermelha, equipada com monitor multiparamétrico, ventiladores respiratórios e demais insumos. Após a estabilidade clínica era coletado RT-PCR e/ou Antígeno (feito no próprio laboratório com laudo liberado até $2 \mathrm{~h}$ ) e acomodados em enfermarias, e em caso de piora clínica, transferido para as Unidades de Terapia Intensiva (UTI).

Com o decorrer da pandemia, o número de casos para COVID-19, fez aumentar o número de coleta (aproximadamente 120/dia), assim, foi necessário formar uma equipe que realizasse toda logística de coleta e envio das amostras para o laboratório terceirizado (RTPCR). Consequentemente, aumentou-se também o número de notificações compulsórias.

Para o SCIH, o laboratório fornecia laudos dos resultados COVID-19, das SRAGHospitalizadas, que eram encaminhadas diariamente para a Vigilância Epidemiológica Municipal, por meio físico; as SRAG em isolamento domiciliar eram preenchidas no formulário eletrônico e-SUS VE e semanalmente encaminhadas através de importações de dados. Ainda para qualificar as ações do SCIH, eram elaboradas planilhas com todos os casos para construção de indicadores que monitoravam a positividades de casos - "covidímetro" e comparava a correlação do RT-PCR e o antígeno.

A seguir, a figura exemplifica o fluxograma da notificação compulsória.

Figura 1 - Fluxograma de notificação compulsória para SRAG e e-SUS feitas pelo SCIH. 

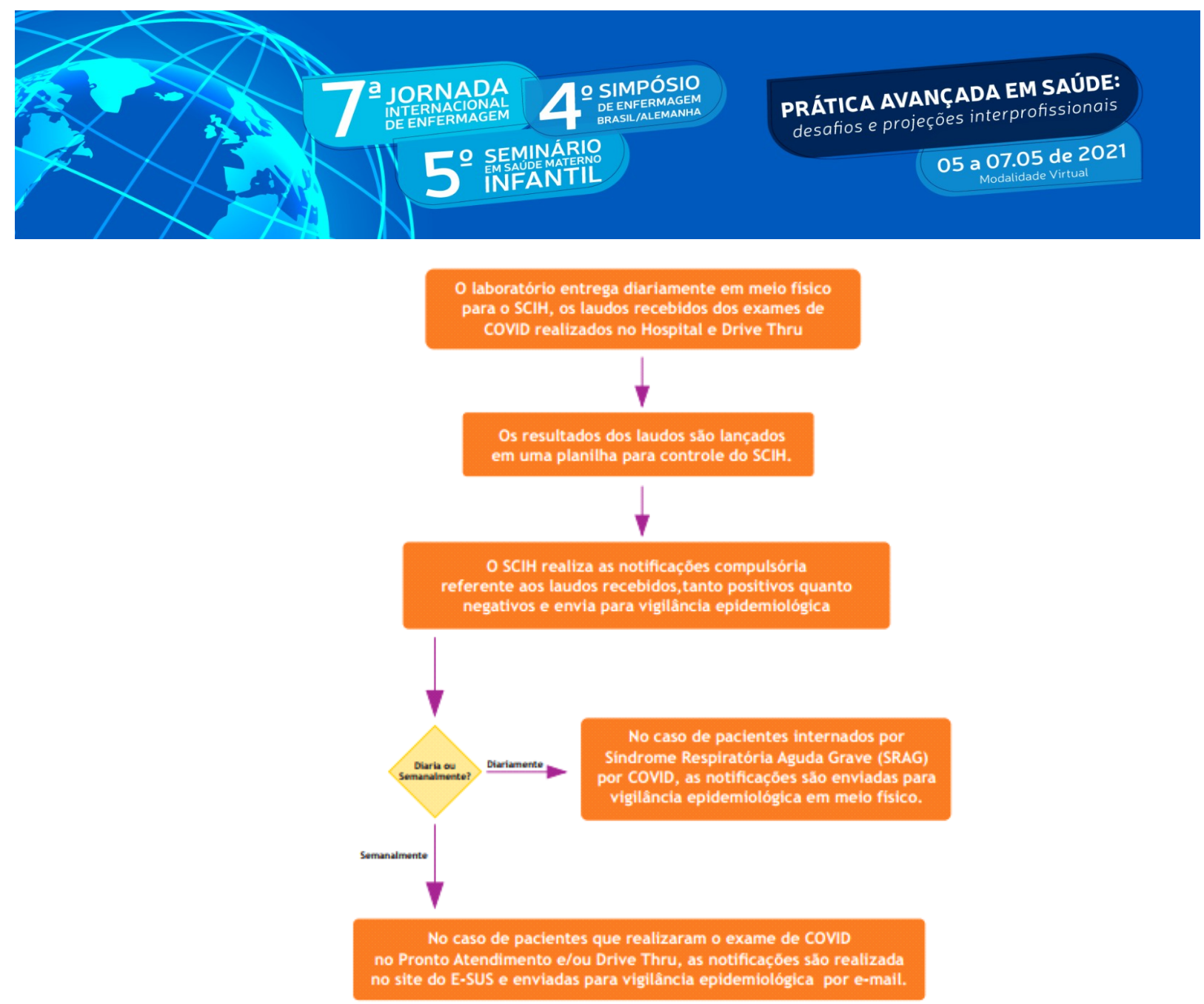

Fonte: próprio autor.

A rotina do $\mathrm{SCIH}$ foi definitivamente alterada com a chegada do COVID-19, e ainda deve permanecer assim algum tempo, tendo em vista que a disponibilização de imunobiológicos para toda a população apresenta-se de forma lenta. O serviço que era composto por um médico infectologista e dois enfermeiros, com a pandemia recebeu mais um enfermeiro e um técnico de enfermagem, objetivando manter a demanda do serviço. Assim, adequações necessárias foram feitas para que não houvesse atrasos nos serviços, acúmulo de pendências, e o negligenciamento de outras atividades competentes ao SCIH em detrimento deste acréscimo de trabalho, principalmente no aumento significativo de notificação compulsória por SRAG.

\section{Desafio na prática do SCIH}

A chegada da pandemia ao SCIH do hospital, fez com que necessitássemos nos reorganizar. Todas as atividades de rotina a serem executadas, foram acrescidas por essa 


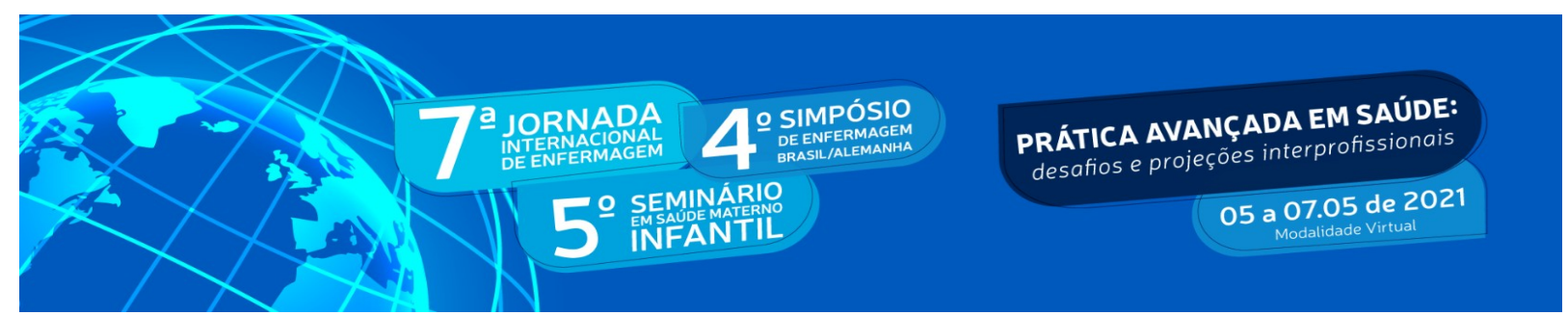

turbulência com novas informações, definições de caso, decretos e portarias que nos atualizavam sobre o novo vírus, quase que diariamente, fez emergir uma sobrecarga para a equipe. Contudo, não foi deixado de dar respostas a tempo/hora das notificações compulsórias, o que oportunizou decisões mais assertivas dentro do hospital.

As contribuições do SCIH para o cotidiano da prática proporcionaram um modelo de tomada de decisão eficaz diante da pandemia da COVID-19, com respostas qualificadas e oportunas. E com a chegada de mais um profissional de saúde para o serviço, as notificações compulsórias de SRAG se mantiveram obedecendo as melhores evidências e fluxos institucionais.

\section{CONCLUSÃO}

$\mathrm{O}$ estudo retratou a vivência da equipe do SCIH formado por médico e equipe de enfermagem durante a pandemia do COVID-19 no caso de notificação compulsória por SRAG.

Mesmo com a contratação do profissional e reestruturação nos demais processos do serviço, a pandemia mostrou-se desafiadora, exigindo uma interconexão entre gestão do cuidado, organização de recursos humanos, insumos e tecnologia, utilização de indicadores epidemiológicos e processos inéditos protocolados no enfretamento do COVID-19.

Nesta experiência, ratificou-se a extrema importância o SCIH. Diante da pandemia de um agravo emergente, atender todas as demandas necessárias para qualquer processo voltado ao controle e assessoramento de infecção hospitalar dentro do hospital, foi e está sendo um desafio para todos.

Fica latente que os processos de tomada de decisão, comunicação e divulgação são grandes desafios, diante dos esforços direcionados para combater a pandemia, e todo o processo assistencial, bem como manter aliada e alinhada a força dos profissionais envolvidos, principalmente do serviço de controle de infecção. 


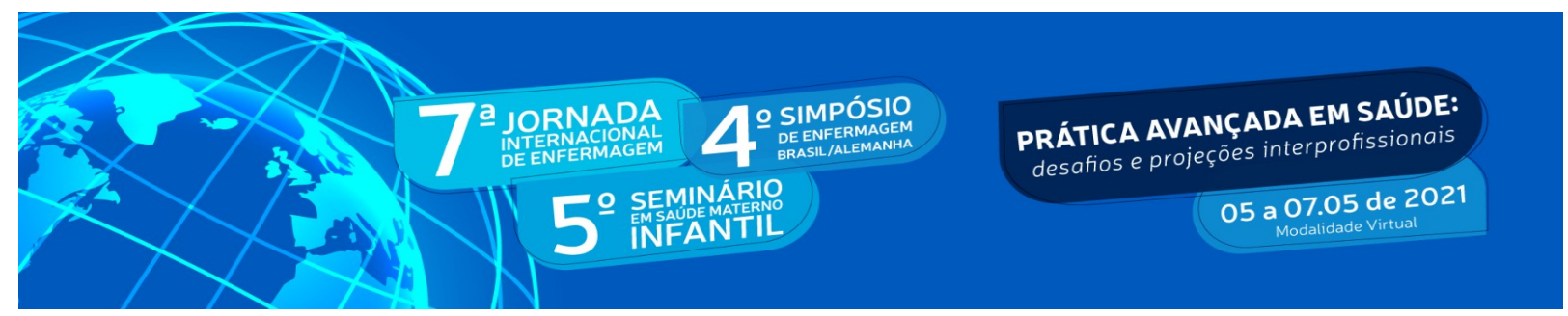

\section{REFERÊNCIAS}

BELARMINO, Adriano da Costa et al. Práticas colaborativas em equipe de saúde diante da pandemia de COVID-19. Brasília: Revista Brasileiro de Enfermagem, 2020.

CUGINI, Daniela Montesi et al. Perfil epidemiológico dos casos de influenza A (H1N1) em Taubaté - SP. São Paulo: Boletim Epidemiológico Paulista, 2010.

LAKATOS, Eva Maria Marconi, Marina de Andrade. Fundamentos de metodologia

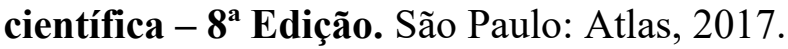

LANA, Raquel Martins et al. Emergência do novo coronavírus (SARS-CoV-2) e o papel de uma vigilância nacional em saúde oportuna e efetiva. Rio de Janeiro: Caderno de Saúde Pública, 2020.

LIMA, Francisca Elisângela Teixeira et al. Intervalo de tempo decorrido entre o início dos sintomas e a realização do exame para COVID-19 nas capitais brasileiras, agosto de 2020. Brasília: Epidemiologia e Serviços de Saúde, 2021.

MINISTÉRIO DA SAÚdE (BRASIL). Gabinete do Ministro. Portaria $\mathbf{N}^{\circ} \mathbf{2 . 2 5 4}$, de 5 de agosto de 2010.

MINISTÉRIO DA SAÚDE (BRASIL). Gabinete do Ministro. Portaria $\mathbf{N}^{\mathbf{0}} \mathbf{2 6 1 6}$, de 12 de maio de 1998.

NIQUINI, Roberta Pereira et al. SRAG por COVID-19 no Brasil: descrição e comparação de características demográficas e comorbidades com SRAG por influenza e com a população geral. Rio de Janeiro: Caderno de Saúde Pública, 2020.

OLIVEIRA, K. T.; CAMANDONI, V. O.; CANTERAS, J. S.; LIMA. J. L., HIRATSUCA, S. Principais medidas tomadas para a mudança dos processos assistenciais durante a pandemia por COVID-19. Brasília: Enfermagem em Foco, 2020.

RIBEIRO AF, Pellini ACG, Yu ALF, Kitagawa BY, Liphaus BL, Abdalla CSS. Influenza A (H1N1) no estado de São Paulo, emergência em saúde pública de importância internacional, resposta articulada, com ênfase na redução de morbimortalidade associada à pandemia. São Paulo: Boletim Epidemiológico Paulista, 2010.

SILVA, Amanda Priscila de Santana Cabral; MAIA, Lívia Teixeira de Souza; SOUZA, Wayner Vieira de. Síndrome Respiratória Aguda Grave em Pernambuco: comparativo dos padrões antes e durante a pandemia de COVID-19. Rio de Janeiro: Ciência e Saúde Coletiva, 2020. 